\title{
Modern process control techniques in the production of dried milk products - a review
}

\author{
Donal O'CALLAGHAN ${ }^{a} *$, Peter CUNNINGHAM ${ }^{b}$ \\ a Dairy Products Research Centre, Teagasc, Moorepark, Fermoy, Co. Cork, Ireland \\ b AMT Ireland, Process Engineering Department, University College Cork, Cork, Ireland
}

Published online 21 June 2005

\begin{abstract}
Advanced process control techniques are being developed for the manufacture of milk powder. Further developments depend on determining with accuracy the multivariate aspects of thermodynamic properties of a concentrated food in the course of milk powder manufacture. Viscosity must be measured and modelled as a function of total solids, temperature, time and shear rate for each product over the range of conditions encountered in the falling film evaporator and the spray dryer, and, in addition, density and heat transfer coefficients must be determined and modelled versus total solids and temperature for spray drying. Some of these parameters are difficult to measure exhaustively, due to the interactive effects of time, temperature and shear rate. Research needs to be directed at characterising the changing thermodynamic properties of milk at all stages in its transformation to powder and at identifying an appropriate mix of first-principle and empirical models. Future developments are likely to involve models for stickiness, thermodynamic models of spray drying, online monitoring of atomisation and measurement / modelling of particle surface conditions.
\end{abstract}

process control / model predictive control / milk powder / spray drying

Résumé - Revue des techniques modernes de contrôle opératoire dans la production de poudres laitières. Des techniques avancées de contrôle de fabrication des poudres laitières sont en cours de développement. Ces développements reposent sur la détermination précise du caractère multivarié des propriétés thermodynamiques du concentré au cours de la fabrication de la poudre de lait. La viscosité doit être mesurée et modélisée en fonction de la teneur en matière sèche totale, de la température, du temps et du taux de cisaillement pour chaque produit sur l'ensemble des conditions rencontrées dans l'évaporateur à flot tombant et dans la tour de séchage par atomisation et, de plus, la masse volumique et les coefficients de transfert de chaleur doivent être déterminés et modélisés en fonction de la matière sèche totale et de la température de séchage par atomisation. Certains de ces paramètres sont difficiles à mesurer de façon exhaustive en raison des effets interactifs du temps, de la température et du taux de cisaillement. La recherche doit s'orienter vers la caractérisation du changement des propriétés thermodynamiques du lait à tous les stades de sa transformation en poudre et vers l'identification d'une combinaison appropriée des modèles du premier principe et empiriques. Les futurs développements impliqueront probablement des modèles pour le collage, des modèles thermodynamiques de séchage par atomisation, le contrôle en ligne de l'atomisation et la mesure/modélisation des caractéristiques de surface des particules.

contrôle de procédé / modèle prédictif / poudre de lait / séchage par atomisation

\footnotetext{
* Corresponding author: djocallaghan@ moorepark.teagasc.ie
} 


\section{INTRODUCTION}

The manufacture of milk powder involves a series of continuous or semi-continuous steps, e.g. milk standardisation, thermal treatment, evaporation, spray drying and fluidised bed drying, each of which has associated process variables which affect the efficiency of the process and/or the quality of the product [26, 31]. While the central control variables are total solids (in evaporators) and moisture (in spray dryers), process conditions influence many powder characteristics, e.g. bulk density, particle size distribution and insolubility index, all of which are subject to specification [14,20, 21]. There is an ongoing evolution of advanced process control techniques, meaning knowledge-based techniques, which take the dynamics of the process into account, being applied to expand the range of control variables, and to improve consistency, in drying processes $[2,6]$. Such advanced techniques have been applied to processes whose thermodynamics are well described mathematically, such as heat exchangers and distillation columns. There are particular challenges in applying advanced techniques in the spray drying of milk, because of:

(a) the multivariate aspects of thermodynamic properties of a concentrated food such as concentrated milk,

(b) the difficulty in accurately modelling changes in these properties in the course of milk powder manufacture,

(c) incomplete knowledge of relationships between process conditions and product characteristics.

Before the advent of computerised control systems, process control schemes consisted of local Proportional Integral Differential (PID) control loops. Such control loops are now implemented digitally, and still make up at least $90 \%$ of all control loops in a typical industrial plant. However, there is growing interest in exploiting the capabilities of computerised control (e.g. PLC) systems to implement more advanced control strategies, such as Model Predictive Control (MPC).

The concept of MPC is similar to human decision-making in that control is based on the prediction of future system behaviour.

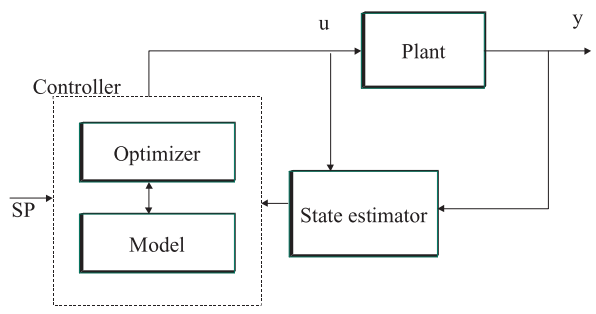

Figure 1. Model predictive control schematic, showing controller with embedded model and an optimiser, which computes a future control strategy, based upon set-point, SP, and model predictions within a future horizon. The "state estimator" is an observer of plant states (current values of the inputs, $u$, and outputs, y). This is, of necessity, faster than the controller, but is sometimes shown as part of the controller.

If plant behaviour is known from past performance, then future plant outputs can be optimised by carefully selecting future inputs. At frequent intervals, the plant state is measured (by online measurements, Fig. 1). An optimum control sequence is calculated within a receding horizon and implementation of this strategy begins and proceeds until further measurements are available, and the cycle is repeated [23]. Unlike earlier control systems, MPC is multivariable, whereas a PID control loop is single-input single-output. In addition, MPC handles input and output constraints, which classical control systems cannot easily handle.

Current approaches to advanced (e.g. model-based) process control in the manufacture of milk powder include the use of empirical and semi-empirical models, and challenges remain in bridging the gap between commercial practice and theoretical approaches. This article reviews the challenges that need to be addressed in bridging this gap.

\section{THE CASE FOR ADVANCED PROCESS CONTROL IN MILK POWDER MANUFACTURE}

Process control in general deals with uncertainty in process behaviour. Advanced 
process control techniques are chosen in order to deal more effectively with uncertainty in process behaviour by incorporating some degree of model prediction. Even with the best available models some uncertainty in process behaviour arises from several sources, e.g. due to unmeasured disturbances, unmodelled dynamics or non-linearities, measurement errors, and actuator errors. The problem is compounded if the thermodynamics of the process cannot be explicitly described in full. However, the incorporation of an approximate process model in a controller can improve the control dynamics.

The larger scale of operation in modern milk powder plants creates a need for better process control. There is greater potential for harm due to out-of-specification product and greater risk in terms of value of lost / downgraded product. It is also more costly to stop/start large plant in the event of a malfunction, such as cyclone blockage, evaporator tube blockage, fluidised bed blockage, etc., any of which could be caused by poor process control. Large-scale plants are more difficult to inspect; hence nowadays, an operator must control a complex process remotely through the use of instruments, analogous to an aeroplane pilot.

The most critical factor creating a need for advanced process control is the changing nature of instrumentation and actuator technology. Variable speed drives are being used more widely, not only for energy efficiency, but also for more precise control and this often introduces interactive effects, which in turn calls for a multiple-inputmultiple-output control system. The widespread use of programmable logic controllers (PLCs) in the food industry leads to a greater emphasis on sequential event-based operations, which need to be integrated with any control strategy [32]. In addition, fuzzy (or rule-based) control, which is used where complex relationships can be represented by a rule that is easy to understand, is easily implemented in PLCs. Fuzzy control can be a useful mechanism for encapsulating the skills of experienced operators. Fuzzy control has been applied to drying processes [7].

A strategic objective with advanced process control is to operate a plant under stable conditions that produce good product characteristics consistently. A consequent, though less significant, benefit is that product yield can be improved through tighter variation on moisture content of the finished product, enabling a given amount of solids to be converted into a slightly greater amount of finished product. Energy savings are also possible through better process control, since thermocompressor efficiency depends on the operating point being close to design conditions.

There have been developments around the concept of fault-tolerant process control, i.e. strategies that minimise the effect of component failures, e.g. actuator and sensor failures, on the quality and safety of the production process. The concept was first developed in parallel with distributed process control, as a means of reducing the risk of failure of the control system itself [1].

\section{PROCESS MODELLING}

\subsection{Steady-state versus dynamic models}

Steady-state models, such as DrySPEC2, can be used to establish process conditions for optimum exploitation of evaporators and/or dryers with regard to energy consumption and powder properties [28]. However, an objective of process control is to achieve stable plant operation, and if this is to be achieved using a process model, then a dynamic model is required for this purpose, i.e. a model that predicts responses to process inputs as a function of time. Such models cover a spectrum between "black-box" and "white-box".

\section{2. 'Black box' models}

Black box models, developed using data extracted from the process, in conjunction with an identification technique (and hence described as a data-driven approach), can be developed with minimal process knowledge [17]. Once sufficient data is available then it is possible to estimate a model. However, a black box model does not contain the physical details of a process and is specific 
to the process plant, operating region and product on which it is developed. For this reason, the effects of changes in product properties, or of process conditions outside of those encountered at the model development stage, cannot be predicted. However, such models have proved particularly effective where critical parameters are identified and measured online. The Fralcomp method is an example of such a scheme, applied to the control of moisture in milk powder [33].

\subsection{System identification}

Modelling dynamic systems from experimental data involves data collection, determination of model structure, estimation of model parameters and model validation. Most models used in MPC are empirical models, "identified" through plant tests, e.g. step responses, pulse responses or random input responses. System identification consists of assuming a model form, and adjusting model parameters to fit the measured data. Typical model forms used include Firstorder-with-delay and Difference-equations. It must be remembered that plant modifications, such as changes to air-swirl arrangements, could necessitate a repeat of system identification.

\section{4. 'White box' models}

A first-principle approach, sometimes known as 'white box' modelling, has been proposed for simulating spray drying and controlling the moisture content based on periodic measurements of water content at the outlet [20]. A first-principle approach has great long-term potential for process control and for training simulators. If the model equations are available, the firstprinciple approach will produce a true dynamic non-linear model and will be fully predictive, even outside of normal operating conditions, although non-linear model predictive control requires special attention to stability [11]. Under some conditions, a suitable linear model can be found which controls a non-linear process as well as a non-linear controller, but without the attendant instability questions (i.e. the process control model in Fig. 2 could be linear,

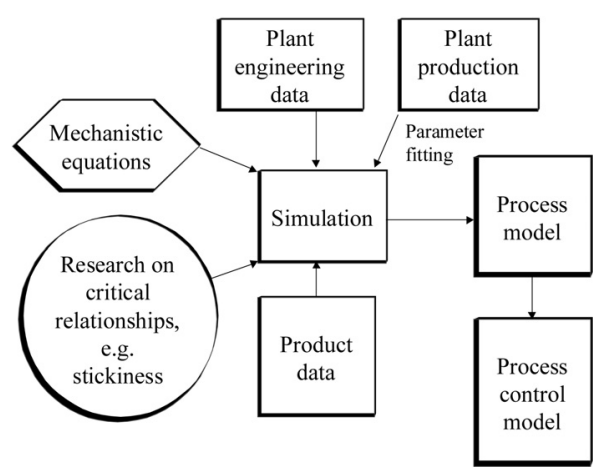

Figure 2. Schematic showing possible role of computer simulation, e.g. CFD, in developing a process model.

although based on a non-linear process model), but it is not clear if that applies to spray drying [18]. Computational fluid dynamics (CFD) simulation techniques can play a role in the development of dynamic process control models (Fig. 2) [29, 34]. A first-principle model could be extended to a range of products by incorporating laboratory data on those products, and to a range of plants by incorporating plant configuration data, assisted by CFD. However, a comprehensive determination of thermodynamic behaviour and relationships is required before the modelling is undertaken. This compares with the situation with empirical models, where complete and exhaustive system identification must be carried out for each product and each plant.

The current state-of-the-art in the modelling of spray drying from first principles is illustrated by attempts at modelling droplet shrinkage and internal temperature profiles in single droplet with an evaporating front which recedes during drying [25]. It was shown that the prediction of droplet temperature at the later stages of drying is critically dependant upon crust thermal conductivity; the accuracy of temperature prediction was of the order of $\pm 10 \mathrm{~K}$ [8].

\section{5. 'Grey box' models}

It is possible to adopt a hybrid approach, combining physical models for process 


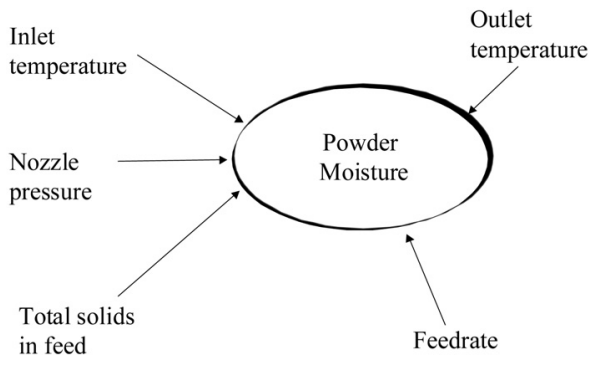

Figure 3. Principle of inferential (or soft) sensor for moisture control. Here, moisture is determined from five input variables, measured on-line.

steps where they are available, with empirical models where exact physical models have not been developed. This is sometimes described as a "grey box" approach, i.e. a combination of "white boxes" and "black boxes". The parameter fitting to plant production data in Figure 2 is indicative of a grey box approach. A hybrid model structure has two main advantages over a pure white box approach:

(i) it provides a way around missing information in a complex system,

(ii) it gives a reasonable trade-off between complexity and performance from a control point of view [4].

This is the most effective approach for modelling spray drying in the short to medium term. It is anticipated that, as further research produces more fundamental models, the empirical components of the grey box models will be replaced with mechanistic (i.e. fundamental) equations.

\subsection{Inferential measurement}

In some situations, product quality, e.g. moisture and insolubility index, cannot be measured readily, but can be estimated / inferred in real time from readily available measurements, allowing for inferential control of product quality (Fig. 3) [27]. The term, 'soft sensors', refers to the use of computer modelling (or inferential) techniques for this purpose. Soft sensors play various useful roles. Chiefly, they predict the effect of process changes before those effects occur, which is a pre-requisite for model predictive control. It has been shown, for example, that insolubility index can be predicted, with the aid of CFD, when the particle size and air outlet temperature are known [30]. Soft sensors can also add robustness to a system by over-riding an instrument reading (e.g. of moisture), where an instrument becomes faulty, an aspect of fault-tolerant process control.

A somewhat related development is the use of intelligent field devices, such as improved actuators that give linearised responses and overcome the effects of wear and dead-time on their responses [13].

\section{CHALLENGES IN PROCESS CONTROL IN MILK POWDER MANUFACTURE}

In general, the application of a first-principle approach to modelling evaporation / spray drying is quite challenging. It involves the use of thermodynamic / fluid dynamic equations to describe heat and mass transfer in terms of online measurements, and the computation of process conditions experienced by each drop of milk as it goes through each processing step before becoming a powder particle. In addition, the relationship between process conditions, e.g. temperature, pressure and shear history, and product characteristics, must be known explicitly, i.e. in a predictive sense. Thermodynamic parameters must be determined and modelled over the range of conditions encountered in the manufacturing process for each formulation being manufactured. This would imply measuring viscosity as a function of total solids, temperature, time and shear rate for a range of products and over the range of conditions encountered in a falling film evaporator [35]. In a spray dryer, density, surface tension, viscosity and heat transfer coefficients would need to be determined in a range of droplet sizes over the range of total solids and temperature at which milk is atomised and dehydrated [22]. Some of these parameters are difficult to measure exhaustively, due to the interactive effects of time, temperature and shear rate. 


\subsection{Viscosity and droplet size distribution}

The rate of heat transfer in a falling film evaporator is a function of viscosity and shear rate. The viscosity of concentrated milk, in turn, depends on the product composition, which is in itself quite complex, as milk contains thousands of proteins and hundreds of fats in many different configurations, and, in addition, on the instantaneous temperature and solids concentration of the milk, the shear rate, and on the thermal history of the milk, as milk concentrate viscosity increases over time, especially if the temperature is over $40{ }^{\circ} \mathrm{C}$ [35]. With regard to atomisation, the physical characteristics of a spray depend on the viscosity of the product at that point [15]. However, the shear conditions at that point are not well defined and would be difficult to replicate in the laboratory. It would be necessary to incorporate on-line measurement of viscosity at, or near, the atomiser. Techniques for doing this are now becoming available. The heat and mass transfer characteristics of droplets in a spray, in turn, depend on the droplet size distribution and change with temperature, solids content and time during drying of the droplets. Some of these product characteristics have been measured under limited ranges of conditions for some products [12]. Perhaps, in the future, it will become feasible to monitor droplet size distribution at the point of atomisation, or to predict the distribution using an inferential approach. At present, this can be done under laboratory drying conditions, or with commercial-scale atomisers on a test rig, but not on-line in a commercial spray dryer.

\subsection{Stickiness}

The control of stickiness of milk powders poses several challenges. It is accepted that a phenomenon generally known as stickiness plays a critical role in the manufacture of milk powder, both in a positive sense, i.e. as a prerequisite to agglomeration, and in a negative sense in causing powder to adhere to contact surfaces (Fig. 4) [19]. Efforts are being made to define,

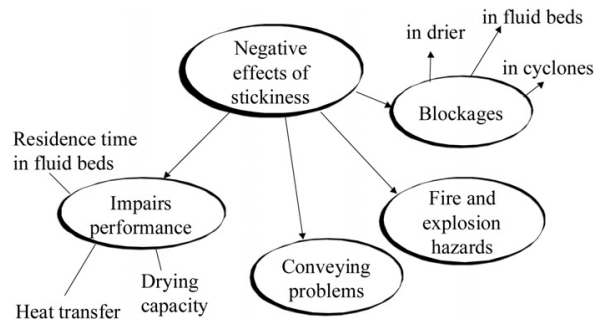

Figure 4. Some negative effects of stickiness in milk powder manufacture.

measure and understand stickiness in a way that relates to its significance in powder manufacture $[3,16]$. It is known that the phenomenon is related to temperature, moisture content and composition [24]. Stickiness is thought to be related to glass transition, which is relatively easy to measure, but the relationship appears to be product specific $[5,10]$.

CFD techniques can play a role in simulating wall deposition [9]. When it becomes possible to model stickiness behaviour sufficiently accurately, such simulations would be able to predict sticky behaviour associated with drying conditions. Such an association could, in turn, be incorporated in a process control model that would minimise the tendency for deposits to form. Further research is needed on sticky behaviour and its relationship to glass transition, and other characteristics of milk powders, with a view to developing a stickiness model that is useful for process control.

\section{CONCLUSION}

Model based process control techniques have emerged in milk powder manufacturing, assisted by the advent of digital control systems, the increasing use of online sensors (e.g. for viscosity), soft sensors and variable speed drives. At present the models in use are mostly empirical models based on plant identification by step response. Progress in advanced process control development depends on a research approach in which knowledge from various disciplines is integrated with a view to bringing together the data 
to generate accurate process models for simulation and control. Further development of MPC in milk powder manufacture needs to be underpinned by a significant effort in the characterisation and measurement of thermodynamic properties of the products being manufactured such as to enable the heat and mass transfer behaviour to be correctly modelled throughout the process. Future developments are likely to involve models for stickiness, thermodynamic models of spray drying, online monitoring of atomisation and measurement / modelling of particle surface conditions.

Research is needed to determine the most critical parameters to be modelled and to identify where a first-principle approach can be applied and in what parts of the process a black box approach will suffice. This, in turn, will help in determining what additional on-line and off-line measurements need to be incorporated in a control strategy and will lead to a control system design.

\section{REFERENCES}

[1] Bastani F.B., Ramamoorthy C.V., Fault tolerant distributed process-control systems, in: Szygenda S. (Ed.), Proceedings of the 1987 Fall Joint Computer Conference on Exploring Technology: Today and Tomorrow (Dallas, Texas, USA), IEEE Computer Society Press, Los Alamos, CA, USA, 1987, pp.522-527.

[2] Blevins T.L., McMillan G.K., Wojsznis W.K., Brown M.W., Advanced Control Unleashed: Plant Performance Management for Optimum Benefit, ISA, North Carolina, USA, 2003.

[3] Boonyai P., Bhandari B., Howes T., Stickiness measurement techniques for food powders: a review, Powder Technol. 145 (2004) 34-36.

[4] Chen L., Hontoir Y., Huang D., Zhang J., Morris A.J., Combining first principles with black-box techniques for reaction systems, Control Eng. Practice, 12 (2004) 819-826.

[5] Chuy L.E., Labuza T.P., Caking and stickiness of dairy-based food powders as related to glass transition, J. Food Sci. 59 (1994) 4346.

[6] Courtois F., Automatic control of drying processes, in: Mittal G.S. (Ed.), Computerized Control Systems in the Food Industry, Marcel Dekker, New York, USA, 1997, pp. 295316.
[7] Davidson V.J., Fuzzy control for food processes, in: Mittal G.S. (Ed.), Computerized Control Systems in the Food Industry, Marcel Dekker, New York, USA, 1997, pp. 179-205.

[8] Farid M., A new approach to modelling of single droplet drying, Chem. Eng. Sci. 58 (2003) 2985-2993.

[9] Harvie D.J.E., Langrish T.A.G., Fletcher D.F., A computational fluid dynamics study of a tall form spray dryer, Trans. IChem E. 80, Part C (2002) 163-175.

[10] Hennigs C., Kockel T.K., Langrish T.A.G., New measurements of the sticky behavior of skim milk powder, Drying Technol. 19 (2001) 471-484.

[11] Henson M.A., Nonlinear model predictive control: current status and future directions, Comput. Chem. Eng. 23 (1998) 187-202.

[12] Hergeth W., Jaeckle C., Krell M., Industrial process monitoring of polymerization and spray drying processes, Polymer Reaction Eng. 11 (2003) 663-714.

[13] Integrated Manufacturing Technology Initiative, Intelligent Controls for Continuous Processing, IMTI Inc., Oak Ridge, Tennessee, USA, 1999.

[14] Jumah R.Y., Mujumdar A.S., Control of industrial dryers, in: Mujumdar A.S. (Ed.), Handbook of Industrial Drying, 2nd edn., Marcel Dekker, New York, USA, 1995, pp.1343-1368.

[15] Kaufmann S.F.M., Feigl K., Fischer P., Windhab E.J., Investigation and visualization of droplet deformation and breakup in complex laminar flow fields, in: Bimbenet J.J. (Ed.), Proceedings of 9th International Congress of Engineering and Food, Montpellier, France, 7-11 March 2004, on CD-ROM, Société de Chimie Industrielle, Paris, France, 2004.

[16] Kudra T., Sticky region in drying-definition and identification, Drying Technol. 21 (2003) 1457-1469.

[17] Ljung L., System Identification: Theory for the User, Prentice-Hall, Englewood Cliffs, NJ, USA, 1999.

[18] Nikolaou M., Misra P., Linear Control of Nonlinear processes: Recent developments and future directions, Comput. Chem. Eng. 27 (2003) 1043-1059.

[19] Ozmen L., Langrish T.A.G., An experimental investigation of the wall deposition of milk powder in a pilot-scale spray dryer, Drying Technol. 21 (2003), 1253-1272.

[20] Perez-Correa J.R., Fariás F. Modelling and control of a spray dryer: a simulation study, Food Control 6 (1995) 219-227. 
[21] Pisecky J., Technology of skimmed milk drying, J. Soc. Dairy Technol. 34 (1981) 57-62.

[22] Pisecky J., Handbook of Milk Powder Manufacture, NIRO A/S, Copenhagen, Denmark, 1997.

[23] Richalet J.A., Rault A., Testud J.D., Papon J., Model predictive heuristic control: applications to industrial processes, Automatica 14 (1978) 413-428.

[24] Roos Y.H., Importance of glass transition and water activity to spray drying and stability of dairy powders, Lait 82 (2002) 475-484.

[25] Santillan Marcus E.A., Tarzia D.A., Exact solutions for drying with coupled phasechange in a porous medium with a heat flux condition on the surface, Comput. Appl. Math. 22 (2003) 293-311.

[26] Schuck P., Spray drying of dairy products: state of the art, Lait 82 (2002) 375-382.

[27] Soroush M., State and parameter estimations and their applications in process control, Comput. Chem. Eng. 23 (1998) 229-245.

[28] Straatsma J., van Houwelingen G., Meulman A.P., Steenbergen A.E., Dryspec2: a computer model of a two-stage dryer, J. Soc. Dairy Technol. 44 (1991) 107-111.

[29] Straatsma J., van Houwelingen G., Steenbergen A.E., de Jong P., Spray drying of food products: 1. Simulation model, J. Food Eng. 42 (1999) 67-72.

[30] Straatsma J., van Houwelingen G., Steenbergen A.E., de Jong P., Spray drying of food products: 2. Prediction of insolubility index, J. Food Eng. 42 (1999) 73-77.

[31] Tetra Pak Processing Systems, Dairy Processing Handbook, Tetra Pak Processing Systems AB, Lund, Sweden, 1995.

[32] Trystram G., Courtois F., Food process modeling and simulation, in: Mittal G.S. (Ed.), Computerized Control Systems in the Food Industry, Marcel Dekker, New York, USA, 1997, pp. 55-85.

[33] van Boxtel A.J.B., Alderlieste P.J., Steenbergen A.E., Control of the moisture content of milk powder by the Fralcomp method, in: Renard M., Bimbenet J.J. (Eds.), Automatic Control and Optimisation of Food Processes, Elsevier Applied Science, New York, USA, 1988, pp. 252-263.

[34] Verdurmen R.E.M., Straatsma H., Verschueren M., van Haren J.J., Smit E., Bargeman G., de Jong P., Modelling spray drying processes for dairy products, Lait 82 (2002) 453-463.

[35] Westergaard V., Milk Powder Technology. Evaporation and Spray Drying, NIRO A/S, Copenhagen, Denmark, 1994. 